\title{
Palabra de los bordes que transita a través: la oralitura como posible apertura político- cultural.
}

\section{Word of the Edges that Transits through the Oral Practice as a Possible Political-Cultural Opening.}

\section{Resumen}

Pensar el lugar de la literatura indígena en el contexto de la Literatura Colombiana, así como dentro de los momentos estéticos de la poesía en el presente siglo, es un ejercicio crítico que plantea un gran desafío, pues implica re-trazar nuestra cartografía cultural y abrir una práctica historiográfica distinta a la que se ha construido hasta hoy. En otras palabras, cuando hablamos de la producción literaria propia de "nuestra geografía", nos referimos a ese cúmulo de textos que se ha divulgado a través de antologías, historias y estudios de la lírica colombiana -siempre parcial, pero con pretensiones de imponerse como total- que siempre ha sido expuesto ("inevitablemente") en las academias y centros de estudios culturales y literarios como el canon. En este sentido, cualquier proyecto que se proponga llevar a cabo un análisis de las propuestas literarias que nos vienen desde lo indígena debe situarse en un umbral, en la liminaridad propia del tema que quiere abordarse y, en consecuencia, debe plantear la posibilidad de generar una apertura, una transformación de ese canon establecido como lo que es, de tal manera que podamos pensar más en lo que debe ser. Así, con la intención de dar cuenta, al menos en parte, de esta imagen más amplia y compleja que se presenta ante nosotros, abordaremos las propuestas hechas por los oralitores Hugo Jamioy (Kamsa), Anastasia Candre (Huitoto) y Estercilia Simanca Pushaina (Wayuu), quienes buscan reivindicar no solo la oralidad como forma de expresión vital por medio de la escritura sino también sus saberes, conocimientos, visiones del mundo, etc.

Palabras claves literatura indígena, cartografía cultural, Oralituras, Poesía indígena, Oralidad. 


\begin{abstract}
Think the place of indigenous literature in the context of the Colombian Literature, as well as within the aesthetic moments of poetry in the present century, it is a critical exercise that poses a major challenge, as it involves re-trace our cultural mapping and open a different historiographical practice which has been built to date. In other words, when we talk about own literary production of "our country", we refer to this cluster of texts that have been reported through anthologies, stories and studies -always partial Colombian lyrical, but with pretensions to impose itself as which has always been completely exposed ("inevitably") in the academies and centers of cultural and literary studies as the canon. In this sense, any project proposed to carry out an analysis of literary proposals that come from the indigenous must be within a threshold, in the very liminality of the topic you want addressed and, therefore, should raise the possibility of generating an opening, a transformation of the fee established for what it is, so that we can think more about what it should be. Thus, with the intention to account, at least in part, of this broader and more complex than is presented to us picture, we will discuss the proposals made by the oralitores Hugo Jamioy (Kamsa), Anastasia Candre (Huitoto) and Estercilia Simanca Pushaina ( Wayuu), who seek to vindicate not only orality as a vital form of expression through writing but also their knowledge, skills, worldviews, etc.
\end{abstract}

Keywords Indigenous literature, Cultural cartography, Oralitures, Indigenous Poetry, Orality.

Pensar el lugar de la literatura indígena en el contexto de la Literatura Colombiana, así como dentro de los momentos estéticos de la poesía en el presente siglo, es un ejercicio crítico que plantea un gran desafío, pues implica retrazar nuestra cartografía cultural y abrir una práctica historiográfica distinta a la que se ha construido hasta hoy. En otras palabras, cuando hablamos de la producción literaria propia de "nuestra geografia", nos referimos a ese cúmulo de textos que se ha divulgado a través de antologías, historias y estudios de la lírica colombiana -siempre parcial, pero con pretensiones de imponerse como totalque siempre ha sido expuesto ("inevitablemente") en las academias y centros de estudios culturales y literarios como el canon. En este sentido, cualquier proyecto que se proponga llevar a cabo un análisis de las propuestas literarias que nos vienen desde lo indígena debe situarse en un umbral, en la liminaridad propia del tema que quiere abordarse y, en consecuencia, debe plantear la posibilidad de generar una apertura, una transformación de ese canon establecido como lo que 
es, de tal manera que podamos pensar más en lo que debe ser. Así, con la intención de dar cuenta, al menos en parte, de esta imagen más amplia y compleja que se presenta ante nosotros, abordaremos las propuestas hechas por los oralitores Hugo Jamioy (Kamsa), Anastasia Candre (Huitoto) y Estercilia Simanca Pushaina (Wayuu), quienes buscan reivindicar no solo la oralidad como forma de expresión vital por medio de la escritura sino también sus saberes, conocimientos, visiones del mundo, etc ${ }^{1}$. De antemano, es importante destacar y aclarar que la tarea que estos autores se proponen, y que es realizada desde los márgenes, en modo alguno busca imponer una autoridad diferente a la ya establecida a causa del resentimiento como único criterio de inclusión, sino que pretenden, más bien desde su práctica discursiva, darle un espacio efectivo a maneras y formas diferentes de concebir la tradición literaria en un país necesitado de oleajes de renovación de sus corpus y cánones, tanto literarios como culturales, éticos y políticos. Todo esto lo consideramos desde la emergencia crítica de lo indígena y de sus saberes ancestrales a partir de su reconocimiento en la constitución política en Colombia en 1991. Esta visibilización de lo indígena sus representaciones, sus "literaturas", sus saberes, su pedagogía- dentro de los espacios académicos y estatales ha revelado cierta inestabilidad del conocimiento que asumimos como válido (el imperante), en donde las estructuras sistémicas tradicionales -como las literarias- ya no son capaces de reinterpretar y replantear las nuevas redes de significación diseminadas que han aparecido estos últimos años. En consecuencia, el proyecto de la oralitura nos ofrece posibilidades nuevas de comprensión, ya que se trata de una propuesta de significación y resignificación cultural producidas desde la sabiduría ancestral indígena, esto es, desde una multiplicidad heterogénea de saberes que no solo tiene mucho que decir, sino que también se encuentra en constante transformación y obedecen a

\footnotetext{
${ }^{1}$ La principal -y quizás mayor problematización- cuando se pretende estudiar estos tipos de literatura estaría cifrada -como bien explica Lienhard- en el ineludible vinculo que tienen estas prácticas escriturarias con una serie de maneras del hacer que no son escriturales como practicas rituales, ceremoniales, orales, de carácter colectivo como las mingas, etc.
} 
"lógicas" distintas a la que ha sido impuesta hasta el momento por los saberes "occidentales".

Es en la emergencia de esos intersticios en donde las prácticas escriturales indígenas se han posicionado y han comenzado a cargar de una altísima ambivalencia la tradición cultural y literaria de la nación: una ambivalencia que surge de la necesidad de construir nuevos territorios alrededor del ejercicio de lo literario -virtuales, imaginados, soñados, pero concretos y materiales, relacionados directamente con la posibilidad habitarlos, de ocuparlos y vivirlosque sean mucho más imprecisos y transitorios; más heterogéneos, móviles e incluyentes. Este ejercicio pasa necesariamente por una apropiación y un uso muy particulares de la palabra, que no es entendida como simple signo abstracto $^{2}$, sino que está dotada de un "poder" particular, que tiene que ver también con la forma en que es usada; de otra forma, podemos decir que hay un ethos del habla en el que se planten usos adecuados e inadecuados de la palabra: palabra que conserva y crea o palabra que produce miseria y olvido. Por esto, la reivindicación de la

${ }^{2}$ Uno de los grandes interrogantes, y por tanto una gran veta para la investigación, es la forma en que las culturas indígenas conciben la palabra. Esta no es pensada ni a la manera de la semiología de Saussure (el signo es aquello que surge de la relación entre un significado y su significante), ni de la forma en que la concibe la semiótica de Peirce (el signo es algo que está por algo para una mente). Si bien ambos sistemas tienen diferencias importantes, ambos comparten, por decirlo de algún modo, el mismo nivel de abstracción, heredado de la "lógica" moderna, que inicia con la cosa en sí kantiana (lo que podemos conocer del mundo son solo sus fenómenos, pero nunca su "esencia"), que termina transformándose en Hegel en una idea compleja y grotesca a la vez: las cosas deben morir en su ser para entrar en el ser del lenguaje. De otra forma, cuando desde nuestro "saber tradicional" se piensa en la palabra-signo, se hace referencia a esa abstracción que asume, de antemano y como principio, el lenguaje como un sistema "independiente" de la "naturaleza" lo que hoy conocemos como giro lingüístico- y, en este sentido, esta palabra-signo es el producto de esa "muerte de la cosa" para que "sea para mí", para que sea "para el hombre". Por el momento, solo podemos decir que el "sistema" al que nos enfrentamos cuando tratamos de abordar el problema de la palabra en el campo de "lo indígena" tiene que ver con una palabra-vida, una palabra viva que es activa y que mantiene una relación singular y necesaria con aquello que nombra. Es decir, no se trata, como ya se dijo, de una simple relación entre un significado y un significante abstractos, sino de una "vibración" (sonora, espiritual, material) que une el nombre con lo nombrado. Podría pensarse en la propuesta elaborada por Benjamin en relación con la idea de la existencia de dos tipos de lenguaje: aquel que reproduce (reactivo, y que puede relacionarse con la palabra-muerte) y aquel que crea (onomatopéyico, y que nombra la cosa). El segundo, que se enmarca dentro de todo el problema de la tradición judía, sería eso que compartimos con los dioses: la capacidad de crear mundo a través del acto de la palabra (acto de habla), una acción, valga la redundancia, que es dar vida a las cosas porque "se las escucha" y gracias a eso "se les puede dar un nombre". 
CATEdRal Tomada: Revista de crítica literaria latinoamericana / Journal of Latin American Literary Criticism Palabra de los bordes que transita a través: la oralitura como posible apertura político-cultural.

palabra como consejo -que presenta Hugo Jamioy en su poesía-, la revisión y reconstrucción de la Chagra y el saber ancestral como fuerza y abundancia de la palabra -realizada por Anastasia Candre- y la toma de conciencia por la defensa de los derechos Wayuu -llevada a cabo por Estercilia Simanca Pushaina a través de sus cuentos- son maneras del hacer, son prácticas a través de las cuales los poetas y escritores indígenas se reapropian de las tradiciones literaria y oral $^{3}$ para abogar por su apertura, ejercicios todos ellos que cuestionan, con razones que van más allá del valor estético y cultural, la literatura y los saberes tradicionales. Es a esta particular articulación a lo que hemos estado llamando oralitura ${ }^{4}$.

Ese doble develamiento (de lo que se presenta como "lo otro" y "lo propio" de lo indígena) puede comprenderse, en parte, como lo que Hommi Bhabha llama "vida en los bordes" (Bhabha 17). Se trata de la emergencia de aquellas formas subrepticias que adquiere la creatividad marginal de grupos o individuos que por mucho tiempo se mantuvieron disidentes, diseminados, viviendo siempre en los límites, con una carente participación política o cultural real en la historia nacional a causa de ciertas relaciones y dinámicas del poder, y que ha dado como resultado que en la actualidad irrumpa una toma de conciencia de agentes inscritos en un universo particular, en este caso el indígena, es decir, de sus miembros autóctonos y originarios por medio de prácticas culturales y sociales. En ese sentido, podemos afirmar que la vida en los bordes "se vuelve el

\footnotetext{
${ }^{3}$ Nuestra investigación parte de la difícil tarea de lo que Martin Lienhard denominó en su texto La voz y su huella. Escritura y conflicto étnico-social en América Latina (1492-1988) (Lienhard) "literaturas alternativas y procesos de transculturación" (Lienhard 148) que es el proceso de prácticas lingüísticas conflictivas que realizan los tres escritores indígenas seleccionados en el trabajo que es la triple operación de codificación oral, recodificación escrita y decodificación científico-crítica. Este artículo se inscribe dentro de un debate crítico relativamente reciente, a la vez que revisita la producción indígena desde una perspectiva interdisciplinaria que potencia el análisis socio-semiótico y cultural.

${ }^{4}$ Es importante tener en cuenta que la oralitura debe ser entendida como un "género" nuevo e independiente, aunque codependiente, de la literatura y la oralidad: independiente en tanto que tiene una visión crítica tanto de lo que podríamos llamar literatura y oralidad "puras", por lo que puede captar tanto sus ventajas como sus desventajas (sus virtudes y sus vicios); pero codependiente en el sentido de que comprende la necesidad tanto de la una como de la otra, en relación con la importancia que ambas constituyen para la posibilidad de mantener vivas tradiciones que, de otra manera, podrían perderse del todo. Este juego ambivalente, esta "doble pinza" como dirían los franceses, es lo que en realidad hace tan importante el movimiento oralitor.
} 
sitio desde el cual algo empieza su presentarse" (Bhabha 21). Pero eso que parece presentarse como un "ejercicio" en y de la periferia, que "avanza" desde los márgenes es una actividad sin firma, anómala y anómica, en el sentido de que no contamos con "categorías" que nos permitan aprehenderla; en este sentido es, a su vez, ilegible. Pero ¿cómo entender estos nuevos develamientos de lo otro dentro de los escenarios culturales en Colombia? Y ¿Qué ha permitido ese "momento intersticial" (Bhabha) ${ }^{6}$ de develamiento de lo "otro" en el escenario nacional, académico, historiográfico, etc.?

Con el establecimiento constitucional del carácter pluriétnico y multicultural de la nación colombiana en 1991, desde los bordes discursivos nacionales emergió un hito histórico que es el develamiento de lo indígena, emergencia cultural y política que significó no sólo la protección y garantía de unos derechos especiales para unas minorías étnicas que no habían sido tenidas en cuenta antes por el Estado nacional, sino porque a partir de esas nuevas políticas públicas establecidas desde los márgenes de la diferencia y la diversidad amparadas por la nueva constitución- las agrupaciones indígenas empiezan a ser percibidas como sujetos productores de cultura con voz y voto haciendo obligatorio el "crear" nuevos espacios de participación cultural/literaria para estas comunidades $^{7}$. A partir de estas reivindicaciones en y desde los márgenes

${ }^{5}$ Es mucho más que un ejercicio, es un conjunto de acciones concretas, de procesos y de propuestas que conllevan a la aparición, a la irrupción de eso marginal en el horizonte social.

${ }^{6}$ Homi Bhabha lo entiendo no como el momento de origen ni el de llegada de "algo" que solo irrumpe en el horizonte social, sino como el momento de una transición. Es decir, entender la forma es que estas nuevas literaturas desde los márgenes discursivos constituyen en el espacio y el tiempo un nuevo ethos literario. Visto así, la visibilización de la literatura indígena - la emergencia de lo indígena como productor cultural- es un proceso de interacción-más allá de que fuera de colaboración o de antagonismo- en donde se abre la posibilidad de la negociación, en donde esos otros elementos que se incorporan -la oralitura, la literatura indígena- al concierto cultural y académico comienzan a tener "verdaderas" posibilidades de agencia en la tradición discursiva occidental.

${ }^{7}$ Las literaturas indígenas buscan configurar un lugar de aparición para "hacerse ver" en otro "espacio" en donde antes no tenía lugar de/para ser vistos y escuchados. Se debe entender que las emergencias literarias indígenas en Colombia en diversos escenarios es "la forma actual de -unamarginalidad -que- ya no es la de pequeños grupos, sino de una marginalidad masiva" (De Certeau, La invención 77) una actividad cultural sin firma, ilegible, que comienza a operar dentro de los marcos de legalidad cultural pretendiendo con ello, la ampliación de lo que entendemos $-\mathrm{y}$ 
nacionales, las literaturas indígenas en Colombia han buscado, dentro de los escenarios nacionales, "ampliar" sus márgenes de visibilidad cultural logrando intervenir sobre lo visible y lo enunciable ${ }^{8}$. Estas revalorizaciones que se dieron a partir de esa visibilización de lo otro $^{9}$ deben entenderse como la aceptación de una pluralidad cultural/literaria que está cifrada en el territorio nacional y en la que en sus actores tengan la posibilidad de procesos de discusión y deliberación frente a la institucionalidad cultural, social y política y que ese "verse" uno y otro en el escenario nacional se convierta en una forma de acción colectiva cuya base sea un proceso de libre manifestación de razones entre iguales ${ }^{10}$ (Santos y Avritzer).

\title{
Hugo Jamioy, Anastasia Candre y Estercilia Simanca Pushaina: Literaturas alternativas.
}

\begin{abstract}
Abordar este tipo de literaturas indígenas ${ }^{11}$ nos lleva a considerar el contrapunto naciones culturales-naciones políticas, ya que son el fruto del encuentro desigual en el marco de un sistema de dominación colonial, lo que develaría que sus prácticas escritas -aquellas literaturas alternativas tanto Jamioy,
\end{abstract}

se entiende- por literatura develando y re-conociendo las "nuevas" configuraciones de la palabra poética que quedaron por fuera del "conteo" inicial.

${ }^{8}$ El modelo de las "literaturas heterogéneas" -como fue denominado por Cornejo Polar (Escribir en el aire)- está fundamentada en la pluralidad etnocultural de las sociedades latinoamericanas y presupone la coexistencia de varios modos productivos. Esos modos productivos logran generar a su vez, producciones simbólicas e imaginarias asociadas a diferentes registros como lo son las practicas discursivas de Hugo Jamioy, Anastasia Candre y Estercilia Simanca Pushaina.

${ }_{9}^{9}$ Desde 1991 se pretendió re-conocer, bajo ciertos órdenes normativos y legales, ciertas realidades sociales, históricas y culturales que habían sido olvidadas $-\mathrm{y}$ negadas- por la institucionalidad nacional.

${ }^{10}$ Se debe hablar desde este punto de emergencia más que de una nación, de naciones; más que de una literatura, de múltiples literaturas.

${ }^{11}$ Literaturas que son el resultado de procesos de interacción cultural desigual entre una cultura hegemónica y una marginal. 
Candre y Estercilia Simanca- exhiben ${ }^{12}$ formas, contenidos y sistemas de comunicación altamente divergentes. Y es allí mismo, que en medio de esta circunstancia límite, estas literaturas han podido preservado parte de su memoria histórica, sus costumbres y rituales, a la vez que han desarrollado un código lingüístico propio $^{13}$. A esta condición heterogénea de su identidad literaria/cultural diacrónicamente entendida, se superponen otras circunstancias sincrónicas, como el hecho de pertenecer a tres comunidades indígenas distintas: Camsta, Wayuu y Huitoto, lo que supondría un juego de representaciones y autorepresentaciones identitarias. Por ello, nuestra tarea se dirigirá a describir y tratar de explicar este mundo, analizando los elementos desarrollados in situ ${ }^{14}$ por estos poetas indígenas, considerando así, las prácticas discursivas de estos tres poetas indígenas como una inscripción local -subcampo cultural y artístico Camsta/Wayuu/Huitoto- de un gran relato centrífugo global indígena cuya reciente patrimonialización se inserta en una especie de movimiento centrípeto de reinvención identitaria ${ }^{15}$.

\footnotetext{
${ }^{12}$ Las literaturas escritas alternativas y marginales, dice Lienhard, "constituyen un objeto de estudio sugestivo en los marcos de proceso de aculturación -y que son- inexplicables fuera de este marco, -porque- ellas configuran un conjunto documental en que las situaciones históricas de enfrentamiento e interacción cultural se ofrecen" a la vista del lector -las cursivas son mías.(Lienhard 135). Claro está, -siguiendo la línea que propone Ángel Rama en su texto Transculturación narrativa en América Latina (Rama), es mejor entender ese proceso de interacción cultural - o como la académica Mary Lous Pratt denomina como zona de contacto (Pratt) como el espacio de los encuentros coloniales, en el que personas separadas por geografía e historia tienen contacto entre sí y establecen relaciones sostenidas, en las que prevalecen la coerción, la inequidad y el correspondiente conflicto- como transculturación.

${ }^{13}$ Lienhard lo denomina como Bilingüismo (Lienhard 140).

${ }^{14}$ En este contexto de búsqueda y de experimentación aparecen varias hipótesis comunicativas de estas literaturas escritas alternativas. La práctica literaria tanto de Hugo Jamioy, Anastasia Candre y Estercilia Simanca Pushainason expresiones particularmente conscientes de la comunicación verbal pero que están atadas a ciertos límites lingüísticos y verbales con ciertas realidades idiomáticas que buscan representar.

${ }^{15}$ Por ello, la oralitura - en este trabajo- debe verse tanto en Hugo Jamioy, Anastasia Candre y Estercilia Simanca Pushainason como una cardinal estrategia de resistencia y preservación de paradigmas ético-estéticos de lo indígena que se instaura como un elemento de cohesión social y cultural. El texto oral/escrito de estos tres poetas cumple la función ritual de reconexión con el tiempo original ab origine de la fundación y cosmización de las comunidades indígenas que representan.
} 
CATEdRal Tomada: Revista de crítica literaria latinoamericana / Journal of Latin American Literary Criticism

Palabra de los bordes que transita a través: la oralitura como posible apertura político-cultural.

La oralitura ${ }^{16}$ de Hugo Jamioy, Anastasia Candre y Estercilia Simanca Pushaina constituye no solo una manera de documentar el pasado, sino un sistema de conocimiento y transmisión que opera bajo tres modos comunicativos, primero, bajo una fuerte inscripción a un horizonte pragmático ${ }^{17}$, segundo, como un modo de eficacia ritual y, tercero, como una forma de dialogismo con lo otro $^{18}$. Por ello, sus producciones orales/escritas representan una instancia cognitiva que tiene un alto contenido ético-didáctico en tanto que es un perpetuador de la axiología comunitaria. En estos tres registros poéticos se advierten no solo voces de distintos surtidores, sino sobre todo sistemas estéticoideológicos conflictivos. Las prácticas de oralituras de Hugo Jamioy, Anastasia Candre y Estercilia Simanca Pushaina no sólo hablan de una batalla social entre etnias, sino que se generan como batallas semióticas y semánticas como textos en pugna consigo mismos ${ }^{19}$.

Por consiguiente, como productos de la oralitura, sus obras siempre resultan complejas de definir. Pero no así los modos cómo operan tanto uno como otro dentro de las escenificaciones culturales nacionales. Sus efectos materiales desestructuración de una producción endógena literaria- y simbólicas desterritorializaciòn y reterritorializaciòn de la palabra- presupondrían ser lo que Néstor García Canclini llamó "narrativas híbridas” (Garcìa Canclini) porque se

\footnotetext{
${ }^{16}$ Para Yoro Fall (Fall) la Oralitura es un término que opera por oposición a literatura y designa textos orales como leyendas, cuentos, epopeyas, cantos y otras producciones artísticas verbales orales menos codificadas en cuanto a su género. Se han hecho muchas referencias a esta producción anfibia de la oralidad que fluctúa entre la voz y la escritura -como la de Martin Lienhard que la denomina "etnoficción" (Lienhard)-. Este género híbrido ha tenido una relativa visibilización dentro las "nuevas" configuraciones historiográficas de las literaturas de América Latina.

${ }^{17}$ El tipo de discurso que insertan estos tres poetas indígenas en sus creaciones literarias y al público al que pretenden dirigirse. Se podría decir que existe un proyecto literario en los tres escritores.

${ }^{18}$ El hibridismo lingüístico tanto de Hugo Jamioy, Anastasia Candre y Estercilia Simanca Pushainaes producto de una realidad "bi-o multilingüe" (Lienhard 151) y que halla exactamente la eficacia comunicativa en esa realidad.

${ }^{19}$ Pensarla como una comunidad hermenéutica que asume instrumentales heterogéneos (Cornejo Polar) implica resignificar el mapa de lo local -sus saberes, prácticas, maneras del hacer, su oralidad- con sus relaciones de "colonialidad" cultural con las metrópolis. Muchos textos latinoamericanos la hibridación es de orientación étnica.
} 
nos presentan como estrategias de entrada, representación y negociación de la modernidad $^{20}$ (García Canclini).

Esta posibilidad se hace evidente con el cuento Manifiesta no saber firmar (nacidos el 31 de diciembre), de Estercilia Simanca, en el que se mezcla la denuncia de la corrupción política, la exclusión social y el abandono estatal a la comunidad Wayuu con la reivindicación de las costumbres, las creencias y los ritos de la misma - la importancia del nombre, del uso de la palabra, de la promesa-. En este caso, el acto literario, o mejor, el acto oralitor -un cuento- se despliega en muchos campos posibles al punto de convertirse en un "producto transmediático": la autora maneja un blog en el que se informa sobre los procesos legales generados como consecuencia del cuento, además de producirse un documental, en el que se pasa de "la ficción narrativa" al "registro histórico". Todo un complejo performático que no acaba con "la palabra fijada en el papel" (o en el espacio virtual del blog), sino que permanece en movimiento, pues se convierte en acto político, social, comunal: un acto estético que deviene "transformación concreta del mundo". Vale la pena citar las palabras de la autora en las que manifiesta las razones que la llevaron a realizar este proyecto:

¿Por qué manifiesta no saber firmar?

Desde pequeña siempre me llamó la atención el que la mayoría de los miembros de mi familia materna manifestaran en sus documentos de identidad "no saber firmar" y que además, todos hayan nacido un 31 de diciembre [...] enseñarlos a firmar, eso sí que sería difícil, por lo que empecé con mi abuelo Valencia Pushaina (Colenshi) de la región de Paradero (Media Guajira). Tenía mi abuelo 70 años de edad, aproximadamente y yo, 7 años, cuando armados de papel y lápiz le di sus primeras lecciones [...] Fue por aquella época cuando llegaron unos cachacos a llevarle un diploma que lo acreditaba como un campesino

${ }^{20}$ La homogenización y neutralización de la diversidad conflictiva propia de toda sociedad moderna. 
CATEDRAL Tomada: Revista de crítica literaria latinoamericana / Journal of Latin American Literary Criticism

Palabra de los bordes que transita a través: la oralitura como posible apertura político-cultural.

colombiano, en el día nacional del campesino. Escuché que mi abuelo debía firmar un recibo que constatara que él había recibido dicho diploma. Me puse en primera fila, estábamos todos en la enramada de la casa de mi tío Ramón (Paraíso, Resguardo Caicemapa, Baja Guajira). De todos yo era la única que esperaba que mi abuelo firmara. Por fin todos se darían cuenta que mi abuelo ya sabía escribir su nombre, pero no le entregaron un lapicero, le tomaron la mano derecha y humedecieron su dedo índice en un huellero y estamparon su huella digital en el recibo. Todos aplaudieron, menos yo [...] Mi abuelo miraba el diploma y hacía como si lo estuviera leyendo, pero no sabía que lo tenía al revés [...] Transcurrió mucho tiempo cuando le pregunté a mi abuelo por qué no había firmado el papel que le dieron los cachacos y me dijo que él ya estaba muy viejo para hablar con el papel (escribir) y tampoco el papel quería hablar con él (leer) [...]". (Consultado en http://manifiestanosaberfirmar.blogspot.com.co)

Se trata, en parte, de hacer justicia, de sacar a la luz un acto discriminatorio. Pero al mismo tiempo, de mostrar la desventaja evidente en la que se encuentra el indígena que no "aprende la cultura del otro". ¿Se trata de un poner por encima uno de los dos "tipos” conocimiento? Más bien su tarea es la de mostrar las desventajas de ambos. No obstante, se mantiene el problema fundamental: situarse en el medio, ver las dos orillas, entender ambas posturas y ser capaces de reivindicar lo que vale la pena de ambos lados. También es importante resaltar la idea de que "no se habla de las cosas", sino que "se habla con las cosas". En este sentido, aquí la palabra se usa como un "artefacto" de intercambio entre quien nombra y lo nombrado: solo puedo nombrar la cosa porque esta me habla, "me dice su nombre", me cuenta su ser; la palabra es un puente que conecta, no solo al hombre con la naturaleza, sino a la naturaleza con 
el hombre, y a los diferentes reinos que componen a la primera entre ellos. No se trata de una relación unívoca sino plural, "multidimensional"21.

Podemos formular una pregunta desde ahora: ¿cuánta importancia puede tener, entonces, hablar bien, mantener los nombres de las cosas, ser consecuentes con esos mismos nombres? La misma Estercilia nos da un buen ejemplo de eso en su cuento:

Ellos tienen nombres extraños [...] También llegó el Candidato, abrazando a todo el mundo y dando besitos a las mujeres, hasta aquellas que ya tenían marido ¿No saben ellos que está prohibido tocar a las mujeres comprometidas y aun a las doncellas que no lo están? Se sabía el nombre de mi tío Tanko, el de mis primos, el de Toushi y Tatuushi, era como si nos conociera desde hace tiempo. Pero cuando Toushi fue llevada hasta el hospital de Uribia y de ahí a Riohacha, mi primo Alfonso López, aprovechando que estábamos en Riohacha, fue hasta su casa a pedir ayuda porque la enfermedad de Toushi era costosa. El señor Candidato ya no se acordaba de él y estaba rodeado de hombres que no dejaban que nadie se le acercara. Creo que el señor Candidato tenía problemas, porque los hombres que lo acompañaban estaban armados hasta los dientes. La casa del señor Candidato también tiene nombre, se llama Gobernación. Pero creo que no es de él, porque cuando pasaron tres veranos ya no vivía ahí. Después vivía otro que se llamaba igual, pero cambian de nombre cuando llegan a vivir a esa casa porque la mayoría termina llamándose "Señor Gobernador". Hay otra casa que se llama Alcaldía y el que vive ahí se llama Alcalde, pero al principio también se llamó igual que el otro... Candidato. ¿No saben ellos que tantos nombres pueden causar confusión? Pero prefiero a Candidato

${ }^{21}$ Esta idea, compleja, de la palabra como puente, como conector de reinos y de mundos, puede verse más claramente en los relatos recogidos en el Babigala. No nos extendemos en este punto por ser muy complejo. Esta es otra línea de investigación posible dentro de toda esta temática. 
porque es bueno. Él regala comida y cuando nos lleva al hospital nos atienden; caso contrario cuando se cambian el nombre por el de Gobernador, Alcalde o Senador, ya no nos conocen. Siento que no sólo cambian el nombre, sino también el alma". (Consultado en http://manifiestanosaberfirmar.blogspot.com.co)

Nombres que saltan de cuerpo en cuerpo, de casa en casa, nombres que no nombran sino que más bien designan, pero que no se fijan ni en el cuerpo, ni en la cosa, ni en la casa. ¿No sabemos acaso que tantos nombres pueden generar confusión? Si nuestro nombre fuera "Hombre que baja de la montaña cargado de fruta" o "Mujer que extrae el néctar de las flores como la abeja", se trataría de "nominaciones" intensivas, cualitativas más que cuantitativas, más que designaciones abstractas que pueden ser cambiadas por otras, sin más. Toda una lección de cómo deben usarse las palabras, o mejor, de cómo no debe hacerse. Pues tanta confusión solo conduce a un destino: la pérdida del mundo, la dislocación de la comunidad, la desaparición de la confianza entre los hombreshermanos.

Esta misma idea de un ethos propio del lenguaje se encuentra en Candre y en Jamioy, y es presentada a través de las palabras yetarafue, en uitoto, y botam biya, en kamsa. La palabra bonita, la palabra de abundancia, la palabra de consejo, esa que está ahí para reconciliarse con la propia cultura, con la madre tierra, no es algo que se dé por sentado. Por el contrario, debe buscarse, se debe “entrar” en ella. Además, no ocupa simplemente un estadio, digámoslo así, de la comunicación, sino que involucra toda una complejidad existencial. Podemos verlo en el siguiente poema de Anastacia:

\section{Soy mujer-sueño}

Como un sueño me engendraron 
soy el sueño de mi madre soy mujer

Cuando era pequeña soñaba palabras bonitas

y la palabra que escuché amaneció

Cuando ya era joven dormía dulcemente

mi sueño se hizo realidad no era sólo un sueño

Soy mujer de despertar verdadera mujer

soy mujer dulce mujer de yuca dulce

mi corazón es como el zumo dulce de la yuca

a las palabras malas las endulzo

como en un sueño

Mi palabra es serena palabra sanadora

Soñé de curaciones y me curé

me fui curando y dormí dulcemente

Amaneció y me desperté alegre

Me sané y pensé en mi trabajo

es mi sueño que se está realizando

No hay persona que no sueñe

toda persona sueña

esos sueños se transforman en abundancia

La palabra de la abundancia

hace trabajar, hace sembrar, no deja dormir

ya no es sueño ya es una realidad

Verdadera mujer madre de las criaturas

soy mujer y mi corazón es dulce

a nadie hago mal

Me despierto bien 
CATEdRal Tomada: Revista de crítica literaria latinoamericana / Journal of Latin American Literary Criticism

Palabra de los bordes que transita a través: la oralitura como posible apertura político-cultural.

con buenas palabras amanezco

sigo adelante con buen corazón

y regreso bien otra vez

Fui bien plantada

tuve buen retoño

crecí bien

florecí bien

di buenos frutos

me cosecharon bien

finalicé en abundancia

Así es mi palabra nunca terminará

no muere perdurará como el viento

Se habla con palabras, pero también se sueña con ellas, se cura con ellas. Somos palabras, o mejor, somos las palabras que nuestros padres soñaron, y a la vez somos nuestros propios sueños, que no son otra cosa que palabras. La palabra es semilla que se siembra, que se cultiva y se cosecha; su campo de arado es simultáneamente el sueño, la conversación, la salud, el futuro... tal vez, la utopía. La vida solo puede ser buena si hemos sembrado buenas palabras, buenos sueños que luego podamos recoger. En este sentido, el poema es mucho más que la descripción de "una vida" o de un "estado de cosas"; es, además de lo anterior, una forma de usar la palabra que consiste en "decretar" la palabra bonita, en "hacer que algo sea" a través de la afirmación de ello en su bondad, en su belleza. Y esto solo puede hacerse si esta palabra "tiene historia", si cuenta los sueños de los abuelos y de los padres, es decir, si trae consigo nuestros saberes comunes y nuestra cultura... si, en fin, conserva lo que somos, si no termina y perdura como el viento.

Jamioy nos repite estas ideas en el siguiente poema: 


\section{Bonito debes pensar}

Bonito debes pensar...

luego, bonito debes hablar.

Ahora, ya mismo,

bonito empieza a hacer.

Se repite, se afianza, la idea de que es necesario un uso particular de la palabra, del pensamiento en este caso, para que aparezca lo bello, para que se dé lo bonito. Para ser bonito se debe pensar igual, pero el pensamiento se da con la palabra, luego, solo hablando adecuadamente se piensa bien y se puede ser de forma correcta. ¿Podría plantearse esto como una especie de imperativo categórico distinto a ese tan cosificador que se nos impuso desde la Alemania iluminada? ¿Puede plantearse una diferencia cualitativa entre ese "deber ver al otro como un fin en sí mismo y no como un medio" y "para ser bello y bueno debes hablar y pensar -y soñar y hacer- bellamente"?

En el siguiente poema, Jamioy muestra qué pasa si se "habla mal":

\section{La muerte}

Uno

La muerte,

de ella no se habla en cualquier momento sino cuando alguien se va por este nuevo camino;

los camëntsá no tienen tiempo

para hablar de ella, 
CATEdRal Tomada: Revista de crítica literaria latinoamericana / Journal of Latin American Literary Criticism

Palabra de los bordes que transita a través: la oralitura como posible apertura político-cultural.

solamente piensan, hablan y hacen la vida

mientras se pueda.

Dos

Si hablamos de ella

la estamos llamando.

Pueda que nos lleve.

Cuando hablamos, lo que está en juego es la posibilidad de ser del mundo. Así, una palabra mal dicha o una intención mal enfocada pueden ser el principio de la catástrofe o de la muerte. La palabra, entonces, se entiende como un ente vivo, que interviene activamente en la forma en que pueden darse las situaciones, en que puede desarrollarse la vida. Se plantea una responsabilidad del habla, pues su acción es la creación misma del mundo ${ }^{22}$. Pero al igual que en Candre y en Simanca, es a su vez el estamento de la conservación, es lo que nos trae y revive la tradición, lo que los antepasados aprendieron sobre el vivir bien, sobre el hablar bien. Como consecuencia de lo anterior, podemos decir que la palabra se convierte en un manto, en un ropaje que nos cubre y nos hace reconocibles pues, a la vez, nos otorga identidad ante quienes son foráneos y nos muestra como "iguales" ante quienes comparten nuestra cultura ${ }^{23}$. No obstante, esta apreciación podría hacernos pensar en que existe una idea hermética de la propia cultura que podría llegar a convertirse en un proyecto identitario excluyente. Pero no hay tal posibilidad. Por el contrario, de lo que se trata, como ya se ha dicho, es de confrontar, de evaluar, de sopesar y poder entender las ideas que existen "en

${ }^{22}$ Se debe ser cauteloso en relación con este tema. No se trata de una ética del discurso como podrían proponerla algunos hermeneutas o filósofos del lenguaje del corte de Habermas. En estos casos, lo que está en juego es la posibilidad del "acuerdo"; su concepción del lenguaje y la palabra es simbólica, esto es abstracta, mientras que en el caso de la oralitura se trata de una palabra viva, que no depende del acuerdo o la convención, sino de la realidad misa de la cosa, del mundo "en sí”.

${ }^{23}$ Vístete con tu lengua: En cada fiesta del viajiy / los taitas van llegando, vienen susurrando su canto. / Vístete con tu lengua /Pueda que a su paso / no te reconozcan... 
ambas orillas del río" ${ }^{24}$. Esta confrontación se hace explícita en poemas como este:

\section{Analfabetas}

A quién llaman analfabetas, ¿a los que no saben leer

los libros o la naturaleza?

Unos y otros

algo y mucho saben.

Durante el día

a mi abuelo le entregaron

un libro:

le dijeron que no sabía nada.

Por las noches

se sentaba junto al fogón,

en sus manos

giraba una hoja de coca

y sus labios iban diciendo

lo que en ella miraba.

\footnotetext{
${ }^{24}$ El agua como espacio de encuentro podría ser un tema a desarrollar, por toda la simbología que envuelve. Resulta interesante pensar en el hecho de que nuestro cuerpo está hecho de agua casi en su totalidad y que sean precisamente el río o la laguna lo que aparece como imagen de lo que nos une. Así será: Los lugares de encuentro / son aguas que hoy / bañan nuestros sentimientos; / mañana tus hijos / y los míos / en la laguna sagrada / nadarán juntos.
} 
Doble tensión: analfabetas los que no saben leer la naturaleza, pero también los que no saben leer los libros. Ya Simanca nos había presentado una situación similar a esta. Sin embargo, Jamioy es contundente al afirmar que "unos y otros algo y mucho saben". No obstante, se hace la denuncia, se pone sobre la mesa la idea de que existen unos que pretenden imponerse sobre los otros, pues no son capaces de entender la diferencia de saberes, las formas distintas que existen de leer, de aprender, de hablar. Un ejemplo del buen hablar: nombrar aquello que es -no ocultar o matizar, no utilizar eufemismos- sin llamar la desgracia. De alguna manera, lo que está en juego -y tomando el riesgo de volvernos repetitivos- es la recuperación del nombre mismo de las cosas, reconocerlas en su "onomatopeya". Puede que sea allí, en ese lugar de los sonidos puros, donde podamos encontrarnos de nuevo como iguales y seamos reconocidos como "hijos legítimos" de la "madre tierra". Quizás sea esta la petición que se hace con estas palabras:

\section{En qué lengua}

Hoy, que me encuentro en su oficina

abogando por la vida de mi pueblo, le pregunto, señor presidente:

¿En qué lengua

están escritos sus sueños?

Parece que están escritos

en inglés, ni siquiera en español.

Los míos están escritos

en camëntsá.

Así 
jamás nos entenderemos.

Aún más que una petición de igualdad, lo que se solicita es la creación de un lugar de encuentro, en los sueños y en consecuencia en la palabra misma: simplemente, debemos hablar con y en la palabra de nuestros antepasados, utilizando el yetarafue, el botaman biya, porque son este tipo de palabras las que nos hacen pertenecer a algún lugar, que nos permiten habitar una tierra, un espacio, y compartir con "esos que hablan y sueñan como uno".

Si todo lo que hemos dicho hasta el momento tiene algún sentido, debemos afirmar que la oralitura sobrepasa con creces un "simple proyecto estético". Por el contrario, la palabra que está envuelta, que está situada en esta dinámica adquiere dimensiones que transitan constantemente en diferentes estratos: estéticos, sí, pero también políticos, culturales, sociales, éticos y pedagógicos. Pero, a pesar de su complejidad, o precisamente por esta, esta oralitura acontece como "una literatura menor", nuevamente, marginal, vista de lejos.

En este sentido, las prácticas poéticas de Jamioy y de Candre y las narraciones breves de Pushaina se encuentran determinadas por la ausencia del poder, esto es, por no contar con una "cuota" que le permita tener "voz y voto" dentro del régimen de lo establecido. Esto conlleva, también, a que carezca de un espacio concreto desde donde pueda actuar (De Certeau, La invención 78), lo que la determina como una lectura periférica. Sin embargo, se presenta, se muestra, se hace visible y nos obliga a -hace necesario- empezar un proceso de redefinición de lo literario dado el carácter heteróclito de la composición social de la cultura y más cuando esta está constituida por múltiples voces que resultan disonantes para el orden discursivo dominante.

La toma de conciencia por la defensa de la tradición ancestral tanto en Jamioy, como en Candre y en Pushaina, ha estado atravesada por ciertas dinámicas culturales que han obligado al orden dominante a re-pensar lo que se 
entendía no sólo como identidad nacional, sino también como literaturas nacionales. A su vez, esto ha generado una inevitable necesidad: la de volver a “cartografiar nuestros propios paisajes íntimos y autóctonos con el propósito de incluir" (Bhabha 102) no solo a los nuevos ciudadanos que están en nuestras fronteras sino también aquellas prácticas discursivas aniquiladas o marginalizadas y "reconocer el impacto tanto económico, financiero, cultural, social y político" (Bhabha 103) de la literatura indígena en la comunidad nacional. Tanto instituciones como academias universitarias han reorganizado sus historias propias, trayendo un nuevo régimen no sólo de prácticas lectoras -poesía indígena, teoría indígena, oralituras, seminarios de literatura indígena- sino también de prácticas ceremoniales de toda índole en donde se celebran abiertamente todos los proyectos escriturales indígenas en recitales y festivales poéticos.

Es importante recalcar que la poesía de Hugo Jamioy, de Anastasia Candre y los cuentos de Simanca Pushaina no se pueden concebir sin sus territorios. Sus palabras -la palabra de abundancia en Candre, la palabra como consejo en Jamioy y la palabra como defensa en Pushaina- son reflejos de sus luchas, de sus travesías en otras geografías -el trasvase de sus lenguas y saberes al español - y que retratan tanto su rebeldía por la defensa de sus saberes ancestrales como el renacimiento intelectual de sus trabajos en el marco cultural, social y político de la nación.

Todos estos trabajos escriturales están construidos bajo diversas rutas que buscan, desde su ejercicio en los bordes, recuperar y preservar sus propias culturas, sus lenguas y su madre tierra. Rutas todas ellas transitadas para construir un texto en el que se logre grabar, transcribir y traducir -como ocurre en Jamioy y Candre- la abundancia del saber. Es allí donde las prácticas de las escrituras propias de las oralituras alcanzan su mayor significación y referencia tanto histórica como cultural.

La palabra poética indígena traducida y trasvasada al español desde los márgenes le da una nueva naturaleza a lo que se venía pensando cómo "lo 
literario" en donde la crítica canónica - ejercida en los centros de alta formación académica- puede encontrar verdaderas revelaciones que permitan que aquellas prácticas diseminadas - de la diáspora- y ausentes de poder tengan un lugar desde dónde actuar y, sobre todo, desde dónde hablar.

\section{Bibliografía}

Anderson, Benedict. Comunidades imaginadas. México. D.F: Fondo de Cultura Económica, (1983).

Bhabha, Homi. El lugar de la cultura. Buenos Aires: Ediciones Manantial. (2002).

Candre, Anastasia. Revista mundo amazónico 5. Colombia: Universidad Nacional de Colombia, 2014.

Chicangana, Fredy. Oralitura indígena como un viaje a la memoria. En: L. M. Lope. (Ed.), "abras de vuelta, oralidad y escritura, experiencias desde la literatura indígena" México: PRODICI, 2014. pp. 73-97.

Cornejo Polar, Antonio. Escribir en el aire. Ensayo sobre la heterogeneidad socioultural en las literaturas andinas. Lima: Editorial Horizonte, 1994.

De Certeau, Michel. La invención de lo cotidiano. México D.F : Universidad Iberoamericana, 2003.

Fall, Yoro. Historiografía, sociedades y conciencia histórica en África. Mèxico D.F: El Colegio de México, 1992. 
CATEdRal Tomada: Revista de crítica literaria latinoamericana / Journal of Latin American Literary Criticism Palabra de los bordes que transita a través: la oralitura como posible apertura político-cultural.

Garcìa Canclini, Nestor. Culturas Híbridas. Estrategias para entrar y salir de la modernidad. Mèxico D.F: Editorial Grijalbo, 1999.

González Piñeros, Nidia. Colombia hacia una democracia participativa. Contribución Indígena 1990-2003. Santiago de Cali: Pontificia Universidad Javeriana, 2006.

Jamioy, Hugo. Bín̈̈be oboyejuayëng / Danzantes del viento. Manizales: Universidad de Caldas - Jabna de América, 2005.

Lienhard, Martin. La voz y su huella. Escritura y conflicto étnico-social en América Latina (1942-1988). Ciudad de la Habana: Ediciones Casa de las Amèricas, 1990.

Pratt, Mary Louise. (2010). Ojos imperiales. Literatura de viajes y transculturaciòn. México D.F: Fondo de Cultura Econòmica.

Rama, Àngel. Transculturaciòn narrativa en América Latina. Buenos Aires: Ediciones El Andariego, 2008.

Ranciere, Jacques. El desacuerdo: política y filosofía. Buenos Aires: Nueva Visión, 2007.

Santos, B. d., \& Avritzer, L. "Introducción: para ampliar en canón democrático". En B. d. Santos, Democratizar la democracia. Los caminos de la democracia participativa Ciudad de México : Fondo de Cultura Económica, 2005. pp. 35-77. 